\title{
Cardiorespiratory Dynamics in Men in Response to Passive Work
}

\author{
Yoshimi NaKazono and Yoshimi MiYamoto* \\ Department of Bio-Medical Control, Research Institute of Applied Electricity, \\ Hokkaido University, Sapporo, 060 Japan
}

\begin{abstract}
Dynamic characteristics of ventilation, cardiac output, and gas exchange in response to passive limb movements were studied in four healthy men in an upright position. Passive exercise was performed on a motor-driven bicycle ergometer, of which pedaling rate was varied from control $(30 \mathrm{rpm})$ to stimulus $(90 \mathrm{rpm})$ level in a stepwise fashion. Stroke volume (SV), heart rate (HR), and cardiac output $(\dot{Q})$ were determined continuously during the exercise by using an automated impedance cardiograph. Minute ventilation $(\dot{V} \mathrm{E})$, respiratory frequency $(f)$, tidal volume $(V \mathrm{~T})$, oxygen consumption $\left(\dot{\bar{O}}_{\mathrm{O}_{2}}\right)$, carbon dioxide output $\left(\dot{V}_{\mathrm{CO}_{2}}\right)$, end-tidal pressure of oxygen and carbon dioxide $\left(P \mathrm{ET}_{\mathrm{O}_{2}}\right.$ and $\left.P \mathrm{ET}_{\mathrm{CO}_{2}}\right)$, and the gas exchange ratio $(R)$ were also determined at each breath. When the pedaling rate was increased, $\dot{Q}$ and $\dot{V}$ E rose in excess of metabolic need with a half response time of about $10 \mathrm{sec}$, and remained elevated for the duration of the stimulus. $\dot{V}_{\mathrm{O}_{2}}$ and $\dot{V}_{\mathrm{CO}_{2}}$ rose transiently, then recovered to the initial control level after a few min. $P_{E^{2} \mathrm{CO}_{2}}$ remained at the control

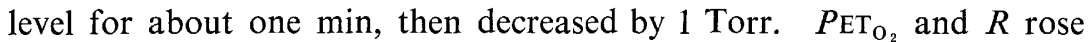
transiently. These results suggest that hyperpnea during passive exercise is not induced by chemical stimuli to known chemoreceptors, but is due to reflexes mediated either by moving limbs or the right heart.
\end{abstract}

Key words: passive pedaling, impedance cardiography, cardiac output, ventilation, exercise hyperpnea.

Since GEPPERT and ZuNTZ (1888) first described an abrupt rise in ventilation immediately after the start of exercise, the mechanism controlling this early increase in ventilation during exercise was remained unknown. When an exercise is performed with a constant load below anaerobic threshold, an immediate increase in ventilation occurs at the start of exercise (fast component), followed after about $20 \mathrm{sec}$ by an exponential rise with a time constant of some $60 \mathrm{sec}$ to a steady-state (slow component). Because of the rapidity of the fast component, the general

Received for publication August 13, 1984

* Present address: Department of Information and Computer Engineering, Faculty of Engineering, Yamagata University, Yonezawa, 992 Japan

中園嘉巳, 宮本嘉巳 
consensus has ruled out the contribution of stimuli to known chemoreceptors, and has ascribed the origin thereof to the neural pathways mediated either centrally or peripherally (DEJOURS, 1964).

Wasserman and his associates (WASSERMAN et al., 1974; WASSERMAN; 1983), however, have proposed another concept in which exercise hyperpnea can occur secondarily to cardiac output $(\dot{Q})$ increase, i.e., cardiodynamic hyperpnea. Simultaneous measurements reveal that neither end-tidal oxygen and carbon dioxide tensions $\left(P_{\mathrm{ET}_{\mathrm{O}_{2}}}\right.$ and $\left.\mathrm{PET}_{\mathrm{CO}_{2}}\right)$ nor the gas exchange ratio $(R)$ change significantly through the transition from rest to exercise. This can only occur when the increase in minute ventilation $(\dot{V} \mathrm{E})$ is matched by a proportional increase in $\dot{Q}$. The increased $\dot{Q}$ or pulmonary capillary blood flow, charged with resting values of $\mathrm{O}_{2}$ and $\mathrm{CO}_{2}$, enhances $\mathrm{CO}_{2}$-flow to the lungs. This would result in an altered $\mathrm{CO}_{2}$ tension in the arterial blood $\left(\mathrm{Pa}_{\mathrm{CO}_{2}}\right)$ if $\dot{V}_{\mathrm{E}}$ did not increase appropriately for the increased $\dot{V}_{\mathrm{CO}_{2}}$. The initial rise in $\mathrm{Pa}_{\mathrm{CO}_{2}}$ is first sensed by peripheral chemoreceptors, the sensitivity of which is expected to intensify during exercise, and a sensitive feed-back mechanism maintains the ventilation-perfusion ratio during exercise the same as that rest (WASSERMAN et al., 1976). Recently, MiYamoto et al. (1982) have evidently confirmed that the time courses of $\dot{V} \mathrm{E}$ and $\dot{Q}$ changes at the transitions from rest to exercise and vice versa coincide with each other in man. However, cardiodynamic hyperpnea may also be explained by another concept based on a feed-forward control mechanism. JONES et al. (1982) found that right ventricular strain correlates linearly with $\dot{V}$ E. An increase in ventilatory drive has also been observed by pulmonary artery distension (LEDSOME, 1977) and right atrium stretch (UCHIDA, 1976). It is likely that mechanoreceptors involved in these organs are activated by the sudden increase of venous return at the onset of exercise, and the reflex from the right heart may provide a direct link between $\dot{Q}$ and $\dot{V}$ E without mediation of any humoral factors.

In the present study, dynamic and steady-state responses of $\dot{V}_{\mathrm{E}}$ and $\dot{Q}$ to passive limb movements were measured in conscious human subjects simultaneously with other variables such as alveolar bas tensions and metabolic rate. Passive limb movement is known to induce an increase in ventilation (COMROE and SCHMIDT 1943; Bahnson et al., 1949; Otis, 1949; Hutt et al., 1958; Benjamin and Peyser, 1964; Biscoe and Purves, 1967; Paulev, 1971; Agostoni and D'Angero, 1976). Until now, reflex from muscle spindles, tendon, or articular organs has been regarded to be a possible drive to hyperpnea (COMroe and SCHMIDT, 1943; BESSOU et al., 1959). Recent neurophysiological evidence, however, has ruled out the contribution of such proprioceptive afferents in exercise hyperpnea in animals (MCCLOSKEY et al., 1972; TIBES, 1977), and instead suggests the possible involvement of fine fibers such as those classified into group III or IV, which may be stimulated by intramuscular pressure or some unknown metabolites (MCCLOSKEY and Mitchell, 1972). Since passive movements require no active muscular contractions, accumulation of metabolites as well as development of intramuscular pressure should be small amount in comparison with active movements assuming 
that the subjects are able to be completely passive. Cortical influences on the response can also be minimized since passive movements are essentially an involuntary maneuver. If the above assumptions were valid, hyperpnea in response to passive movements would mainly be induced by the preceding increase in cardiac output. The kinetics of $\dot{Q}$ during passive work have not yet been described in man so far as we aware.

\section{METHODS}

Cardiac output was determined by an automated measuring system based on impedance plethysmography. A detailed description of this system and evaluation concerning its accuracy have already been published elsewhere (MIYAMoro et al., 1981b). Transthoracic impedance was measured by a standard constant current type impedance plethysmograph (Nihon Kohden, model RGA-5). An electrocardiogram (ECG) was also monitored from the chest wall with bipolar electrodes. A microcomputer system (CPU Z-80, $48 \mathrm{~K}$ bytes) sampled the first derivative $(\mathrm{d} Z / \mathrm{d} t)$ and basic values $\left(Z_{0}\right)$ of the transthoracic impedance at the rate of 200 times/sec when triggered by the $\mathrm{R}$ wave of ECG. The sampling was repeated for 4 to 5 cardiac cycles, and $\mathrm{d} Z / \mathrm{d} t$ and $Z_{0}$ signals were summed to obtain respective averaged waveforms. The subjects were allowed to breath spontaneously during the period of sampling. Since the number of cardiac cycles involved in an ensemble average was not large enough for the complete elimination of respiratory artifact, the impedance signals were partially distorted by the lung volume change. This error was however cancelled from the final records because an exercise protocol was repeatedly studied for each subject and all results were superimposed as described later. Stroke volume (SV) was computed according to the formula of KUBICEK et al. (1966). Heart rate (HR) was derived from the R-R interval of ECG. HR times SV gave minute cardiac output $(\dot{Q})$.

Respiratory frequency $(f)$, tidal volume $(V \mathrm{~T})$, minute ventilation $\left(\dot{V}_{\mathrm{E}}\right)$, endtidal pressures of oxygen and carbon dioxide $\left(P_{\mathrm{ET}_{\mathrm{O}_{2}}}\right.$ and $\left.P_{\mathrm{ET}_{\mathrm{CO}_{2}}}\right)$, oxygen uptake $\left(\dot{V}_{\mathrm{O}_{2}}\right)$, carbon dioxide output $\left(\dot{V}_{\mathrm{CO}_{2}}\right)$ and the respiratory gas exchange ratio $(R)$ were also obtained automatically by a second computer system. A detailed description of this system has been published elsewhere (Мгунмото et al., 1981a, 1982). The impedance pneumograph used in the previous study (Мгуното et al., 1982) was replaced by a hot-wire type pneumotachograph with a small dead space of $10 \mathrm{ml}$. The output signal of this instrument was confirmed to be linear within the physiological range of input flow variations. The composition of expired air was continually analyzed by mass spectrometry (Medspect, model MS-8).

Four healthy young male volunteers, ranging in age from 22 to $25 \mathrm{yrs}$, in weight from 55 to $60 \mathrm{~kg}$, and in height from 163 to $171 \mathrm{~cm}$, were studied. The subject was seated on a bicycle ergometer (Monark) and breathed room air through a pneumotachograph. The ergometer was coupled to an electric motor via a gear- 

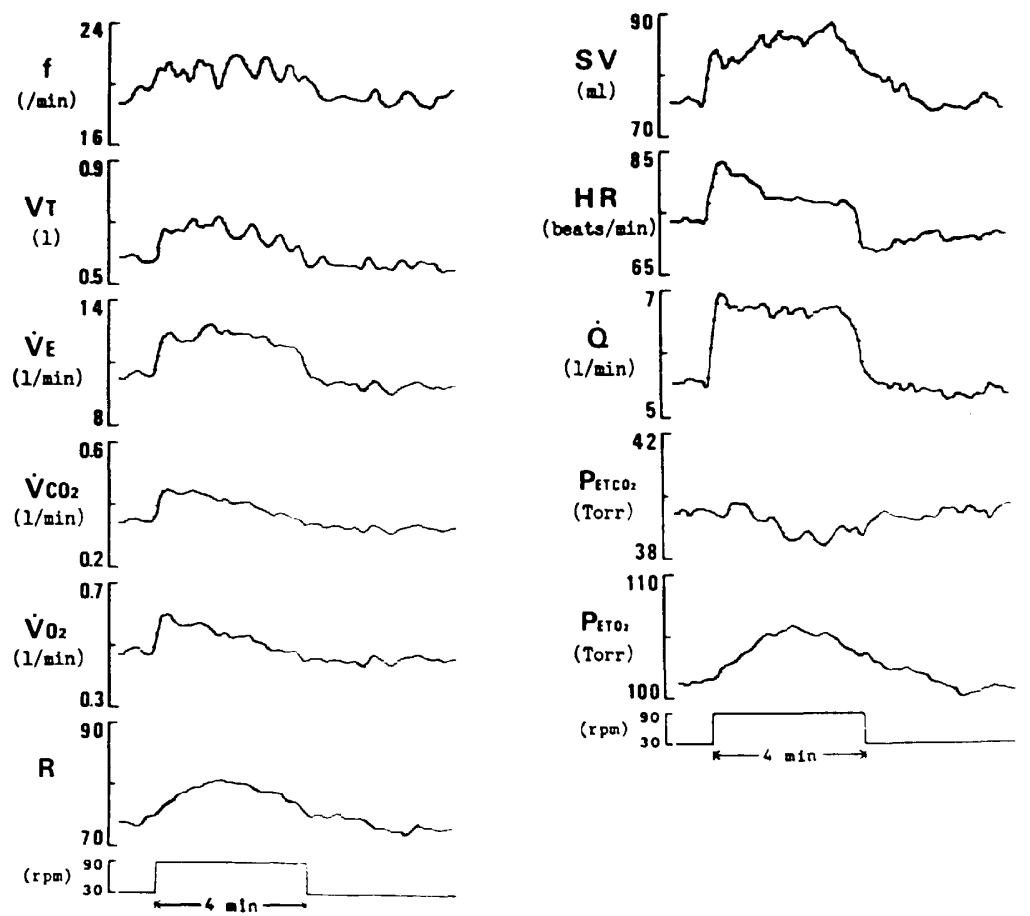

Fig. 1. Typical cardiorespiratory responses to passive pedaling in subject Y.N.

box that provided constant-rate pedaling. The subject's feet were fastened tightly to the pedals. He was previously instructed to relax his legs as much as possible during the run and not to resist against the pedal movement. The experimental protocol consisted of a control low speed pedaling $(30 \mathrm{rpm})$, a stimulus high speed pedaling $(90 \mathrm{rpm})$, and a recovery low speed pedaling $(30 \mathrm{rpm})$, each lasting for periods of $4 \mathrm{~min}$.

The protocol was repeated at least 18 times for each subject with an interval of about $10 \mathrm{~min}$. The maximum duration of the exercise performed in 1 day was limited to $1 \mathrm{hr}$. The individual variables for each subject were first stored in a disk memory together with timing signal for exercise protocol. Since the responses of these variables were rather small, all runs for each subject were averaged on a time-weighted basis at $5 \mathrm{sec}$ intervals.

\section{RESULTS}

Figure 1 illustrates the superimposed responses of eleven cardiorespiratory variables for subject, Y. N. Immediately after the pedaling rate was increased up to the stimulus level, $\dot{V} \mathrm{E}, \dot{V}_{\mathrm{O}_{2}}$, and $\dot{V}_{\mathrm{CO}_{2}}$ increased significantly while $P_{\mathrm{ET}_{\mathrm{CO}_{2}}}$ remained almost unchanged. Both the increase in $V \mathrm{~T}$ and $f$ were responsible for the 


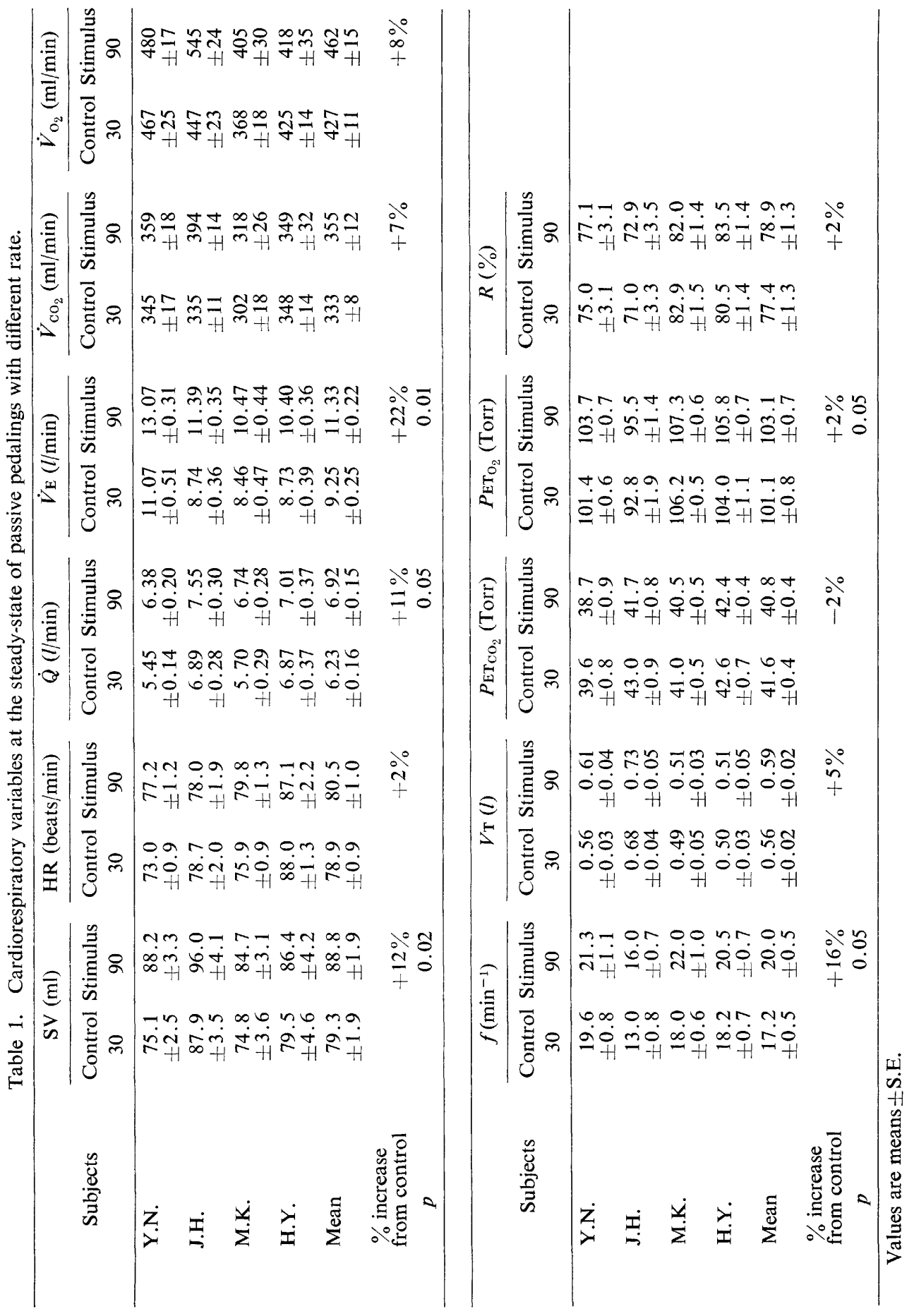

Vol. 35, No. 1, 1985 
abrupt increase in $\dot{V} \mathrm{E}, \dot{V}_{\mathrm{O}_{2}}$, and $\dot{V}_{\mathrm{CO}_{2}}$ returned to the respective control values after about $1 \mathrm{~min}$, while $\dot{V} \mathrm{E}$ remained elevated as long as the stimulus was given. Since the falling rate of $\dot{V}_{\mathrm{O}_{2}}$ was more rapid than that of $\dot{V}_{\mathrm{CO}_{2}}$, reflecting the difference between the storage capacities of these gases in the body tissue, $R$ increased transiently. $\dot{Q}$ also increased abruptly and remained at the high level during the entire stimulus period. Compensatory response of $\mathrm{HR}$ to $\mathrm{SV}$ response contributed to maintain the raised level of $\dot{Q}$ during the stimulus. The initial responses of several variables of interest for subjects $\mathrm{Y}$. N. and J. H. are illustrated with an elongated time scale in Fig. 2. The response values were normalized by using respective control values. $\quad \dot{V} \mathrm{E}, \dot{V}_{\mathrm{CO}_{2}}$, and $\dot{Q}$ increased at the onset of the stimulus with a half response time less than $10 \mathrm{sec}$. The kinetics of these variables were in approximate accordance up to the first $20 \mathrm{sec}$. In contrast, $P_{\mathrm{ET}_{\mathrm{CO}}}$ was fairly constant during the first $60 \mathrm{sec}$. Table 1 summarizes the steady-state values of the variables at the control and stimulus pedalings. These were determined by taking the mean values of the last $1 \mathrm{~min}$ of low and high pedaling periods. The steady-state stimulus values which were statistically different from the control values were: $\mathrm{SV}$ increased by $12 \%(p<0.02), \dot{Q}$ by $11 \%(p<0.05), \dot{V} \mathrm{E}$ by $22 \%(p<0.01), f$ by $16 \%(p<0.05)$, and $\mathrm{PET}_{\mathrm{O}_{2}}$ by $2 \%(p<0.05)$. Figure 3 shows the averaged responses of $\dot{V} \mathrm{E}$ and $\dot{Q}$ for all 72 runs studied in four subjects. The kinetics of both variables were in good accordance through the whole time course of the exercise protocol.

\section{DISCUSSION}

It has generally been accepted that passive motion of the limbs induces hyperpnea in animals (Comroe and Schmidt, 1943; Agostoni and D'Angelo, 1976) and in humans (Comroe and SChMidt, 1943; BAhnson et al., 1949; OTIS, 1949; Hutt et al., 1958; Dejours, 1964). OTIS (1949) found that extension and flexion of the lower limb produced by external force caused a $40 \%$ increase in $\dot{V}$ E while $\dot{V}_{\mathrm{O}_{2}}$ increased only by $10-20 \%$ from resting. A significant increase in respiratory frequency seemed mainly responsible for the hyperpnea. End-tidal $P_{\mathrm{CO}_{2}}$ showed a slight decrease from 0.5 to 1 Torr during the steady-state of passive movements. Similar findings were obtained in conscious human subjects using a motor-driven bicycle (Bahnson et al., 1949; Otis, 1949; Benjamin and Peyser, 1964; Paulev, 1971). It is likely that the subjects are unable to be completely passive but unconsciously resist against the applied forces to some degree, resulting in a slight increase in $\dot{V}_{\mathrm{O}_{2}}$.

We observed that $\dot{V}$ increased by $22 \%$ while $V_{\mathrm{O}_{2}}$ increased by only $6 \%$ (not statistically significant in amount exceeding the control) during the steady-state of stimulus period (Table 1). This corresponded to an alternation in the ventilation equivalent of $\mathrm{O}_{2}\left(V \mathrm{E} / V_{\mathrm{O}_{2}}\right)$ from 21.3 to 24.5 . Thus, the passive pedalings apparently increased ventilation in excess of metabolic need. Hyperpnea which is not accompanied by a proportional increase in $\mathrm{O}_{2}$ consumption has been ob- 

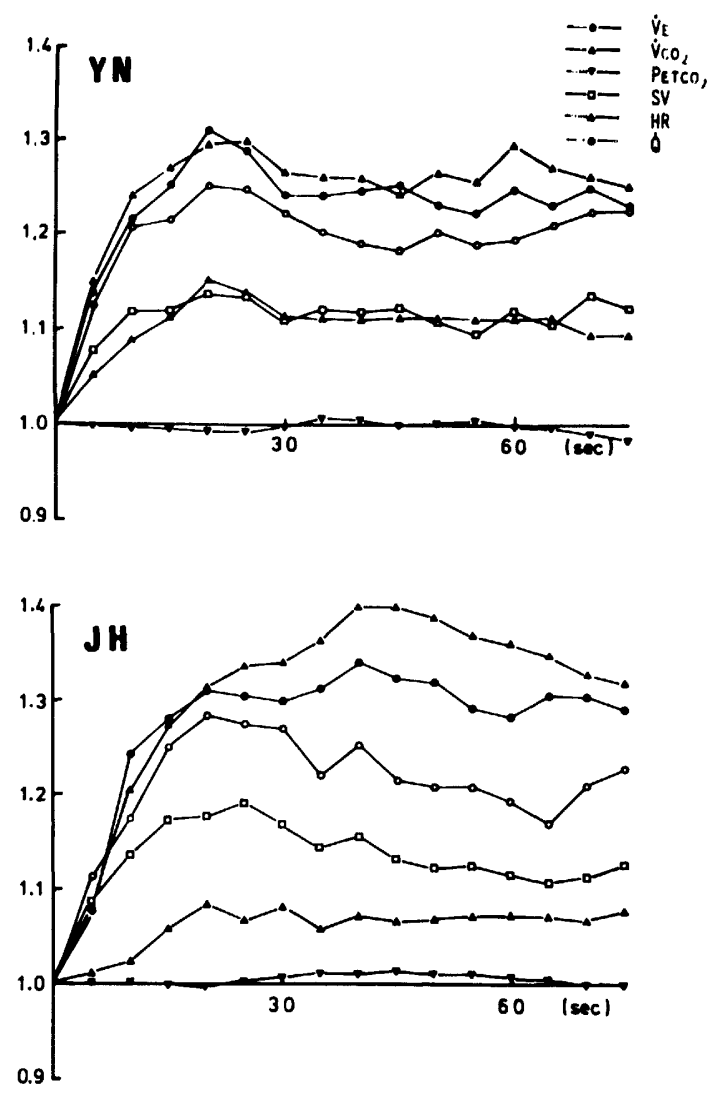

Fig. 2. Representative cardiorespiratory responses to passive pedalings with stimulus rate for subjects Y.N. and J.H., from the start of stimulus to the first $60 \mathrm{sec}$. Values are normalized by using respective control values.

served in conscious human subjects during passive limb movements (COMROE and Schmidt, 1943; Otis, 1949; Hutt et al., 1958; Dejours, 1964; Benjamin and Peyser 1964).

The kinetics of ventilation observed during passive exercise are similar to that of the "fast component response" to active constant load exercise in the rapidity of the response at the stimulus onset. The initial kinetics of respiratory variables also coincide with that of cardiac output. Several different mechanisms may be considered as possible regulatory systems to govern ventilation and circulation during passive exercise. First, reflex arising from the moving limbs to the respiratory and circulatory centers may occur independently but simultaneously. BisCOE and PuRves (1967) observed in anesthetized cats that the respisatory response with passive hind-limb movements was abolished if the femoral and sciatic nerves are cut. Since both the activities of the carotid body afferents and the cervical sympathetic 

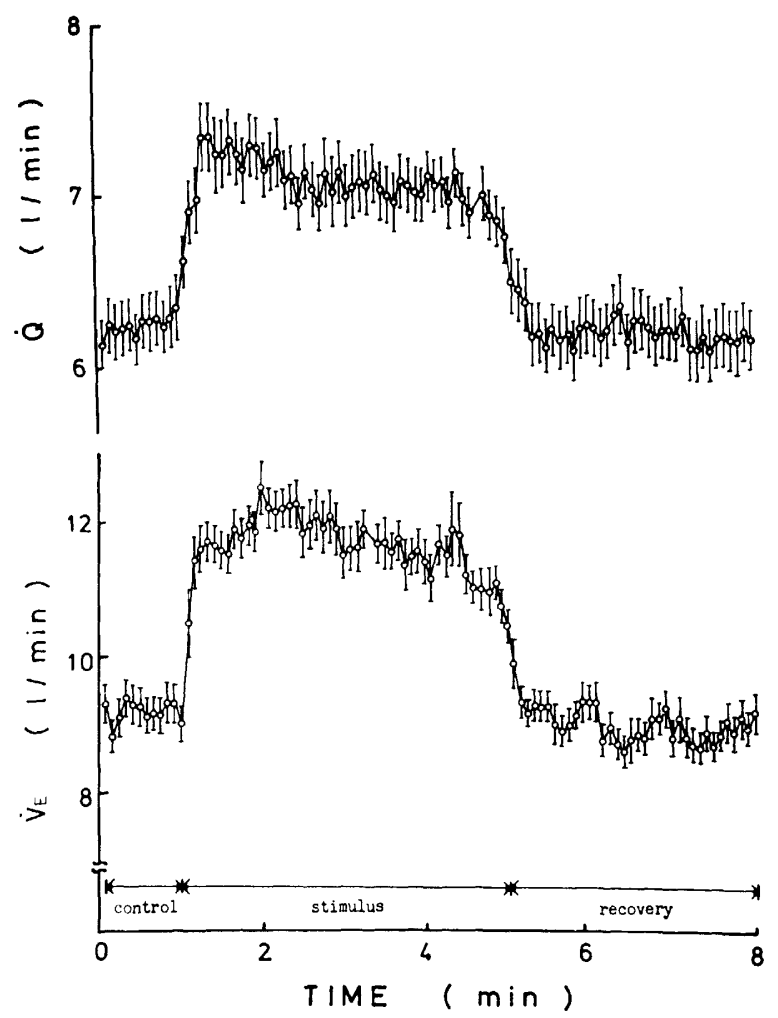

Fig. 3. Superimposed averaged responses of minute ventilation and cardiac output to passive pedalings. Points represent mean value of all 72 runs for 4 subjects and bars represent ranges of S.E.

efferents increased immediately when the limbs were moved and were maintained at an elevated level during the stimulus period, they suggested that the rapid rise in chemoreceptor activity and the corresponding increase in ventilation were driven by increased sympathetic tone activated by the limb afferents. Asmussen and his associate (ASMUSSEN et al., 1943; ASMUSSEN and NIELSEN, 1948) also showed that an increase in heart rate and arterial blood pressures could be caused by sympathetic activity within 1 to $2 \mathrm{sec}$ after starting voluntary exercise. Thus, we cannot rule out the possibility that both the reflexes in respiratory and circulatory control systems occur simultaneously upon initiation of exercise.

In addition, it is also possible that the proportional increase in $\dot{V} \mathrm{E}$ and $\dot{Q}$ at the start of exercise may be driven by the central nervous system which stimulates both the centers of respisation and circulation simultaneously. KROGH and LiNDHARD (1913) attributed the abrupt cardiorespiratory responses at the very beginning of exercise to an irradiation of impulses from the motor cortex to the respiratory and circulatory centers in the medulla. Recently ELDRIDGE et al. (1981) and DiMARCo 
et al. (1983) demonstrated that with induced exercise in anesthetized cats, stimulation of the subthalamic locomotion region caused arterial pressure and ventilation to increase just before the onset of actual limb locomotion.

We observed that whereas $\dot{V}_{\mathrm{E}}$ increased significantly, there was no appreciable change in $P_{\mathrm{ET}_{\mathrm{CO}}}$ until the first min had elapsed. Isocapnia of alveolar gas may be explained by proportional increase in $\dot{V}_{\mathrm{CO}_{2}}$ and $\dot{V}_{\mathrm{E}}$ during the initial period (Fig. 2). Since the initial increase of $\dot{V}_{\mathrm{O}_{2}}$ and $\dot{V}_{\mathrm{CO}_{2}}$ disappeared at the later period of stimulus, passive pedaling did not require as large an $\mathrm{O}_{2}$ consumption as that observed at the initial period. We assume that the initial rise would chiefly be produced secondarily as the result of increased $\dot{V}$ E. Simultaneously increased $\dot{Q}$ would transport $\mathrm{CO}_{2}$ from the body to the lungs until the tissue store of the gas had been exhausted, and at the same time taking $\mathrm{O}_{2}$ into the pulmonary circulation from the alveoli. Since the passively moving limbs actually required $\mathrm{O}_{2}$ consumption equivalent to its steady-state level, $P_{\mathrm{ET}_{\mathrm{O}_{2}}}$ rose. On the contrary, $P_{\mathrm{ET}_{\mathrm{CO}_{2}}}$ did not fall immediately but remained at the initial level for a relatively long period because of the large storage capacity of the body for $\mathrm{CO}_{2}$. In the latter period of stimulus, however, the increase in $\dot{V}$ E occurred in the presence of reduced $P_{\mathrm{ET}_{\mathrm{CO}_{2}}}$ and enhanced $P_{\mathrm{ET}_{\mathrm{O}_{2}}}$ elevation; both in other circumstances should depress ventilation. Thus, the third possibility that peripheral chemoreceptors may be stimulated by $\mathrm{CO}_{2}$ is ruled out. WASSERMAN et al. (1975) reported that the fast component of ventilatory response to active exercise observed in carotid body resected men was not significantly different from controls. It might be possible that the transient increase in $\dot{V}_{\mathrm{O}_{2}}$ and $\dot{V}_{\mathrm{CO}_{2}}$ at the initial period of stimulus was a true reflection of active muscle metabolism; the subject initially fighting against pedal movements, then relaxing at a later time. This can be ruled out because $\dot{V}_{\mathrm{O}_{2}}$ and $\dot{V}_{\mathrm{CO}_{2}}$ fell below the initial control level after stimulus was removed (Fig. 1). This phenomenon is usually observed immediately after voluntary hyperventilation to compensate for the imbalance between metabolic and respiratory gas exchanges.

The most important finding of the present study is the proportional changes in cardiac output and ventilation. Time course of both the variables coincide well with each other not only at the start but also at the end of stimulus (Fig. 3). The increased $\dot{Q}$ during the steady state of stimulus is almost entirely dependent upon an increase in SV, with little change in HR (Table 1). BenJamin and Peyser (1964) also reported that the increase in $\dot{V}$ E accompanying passive exercise did not produce a corresponding increase in HR. The leg movements, either passive or active, would introduce previously pooled blood in the legs and viscera into the general circulation. In passive exercise, however, HR does not rise appropriately in response to the increased venous return because of the lack of effective sympathetic stimuli. This necessarily results in a dominant increase in filling volume and SV. The present observation leads to the conclusion that reflex arising from the right heart is possibly involved in the mechanism to cause the hyperpnea during passive movements. The extent to which the putative reflex interacts with the other re- 
flexes from the moving limbs and the central commands awaits further investigation.

This work has been supported in part by a Grant-in-Aid for Scientific Research from the Ministry of Education, Science and Culture of Japan (No. 59127034 and 59570320).

\section{REFERENCES}

Agostoni, E. and D'Angelo, E. (1976) The effect of limb movements on the regulation of depth and rate of breathing. Respir. Physiol., 27: 33-52.

Asmussen, E., Christensen, E. H., and Nielsen, M. (1943) Humoral or nervous control of respiration during muscular work. Acta Physiol. Scand., 6: 160-167.

Asmussen, E. and Nielsen, M. (1948) Studies on the initial changes in respiration at the transition from rest to work and from work to rest. Acta Physiol. Scand., 16: 270-285.

Bahnson, E. R., Horvath, S. M., and Comroe, J. H., Jr. (1949) Effects of active and 'passive' limb movements upon respiration and $\mathrm{O}_{2}$ consumption in man. J. Appl. Physiol., 2: 169-173.

Benjamin, F. B. and Peyser, L. (1964) Physiological effects of active and passive exercise. $J$. Appl. Physiol., 19: 1212-1214.

Bessou, P., Dejours, P., and Laporte, Y. (1959) Effets ventilatoires réflexes de la stimulation de fibres afférentes de grand diamètre d'origine musculaire chez le Chat. Compt. Rend. Soc. Biol., 153: 477-481.

Biscoe, T. J. and Purves, M. J. (1967) Factors affecting the cat carotid chemoreceptor and cervical sympathetic activity with special reference to passive hind-limb movements. $J$. Physiol. (Lond.), 190: 425-441.

Comroe, J. H. and Schmid, C. F. (1943) Reflexes from the limbs as a factor in the hyperpnea of muscular exercise. Am. J. Physiol., 138: 536-547.

Dejours, P. (1964) Control of respiration in muscular exercise. In: Handbook of Physiology, Sec. 2, Respiration, ed. by FenN, W. O. and RaHN, H., Vol. I, pp. 631-648.

DiMarco, A. F., Romaniuk, J. R., Euler, C. von, and Yamamoto, Y. (1983) Immediate changes in ventilation and respiratory pattern associated with onset and cessation of locomotion in the cat. J. Physiol. (Lond.), 343: 1-16.

ELDRIDGE, F. L., MilhorN, D. E., and WALDROP, T. G. (1981) Exercise hyperpnea and locomotion: Parallel activation from the hypothalamus. Science, 211: 844-846.

GepPert, J. and Zuntz, N. (1888) Ueber die regulation der Atmung. Arch. Ges. Physiol., 42: 189-245.

HUtT, B. K., Horvath, S. M., and SpurR, G. B. (1958) Influence of varying degree of passive limb movements on respiration and oxygen consumption of man. J. Appl. Physiol., 12: 297-300.

Jones, P. W., HuszczuK, A., and Wasserman, K. (1982) Cardiac output as a controller of ventilation through changes in right ventricular load. J. Appl. Physiol.: Respir. Environ. Exercise Physiol., 53: 218-224.

Krogh, A. and Lindhard, J. (1913) The regulation of respiration and circulation during the initial stages of muscular work. J. Physiol. Lond., 47: 112-136.

Kubicek, W. G., Karnegis, J. N., Patterson, R. P., Witsoe, D. A., and Mattson, R. H. (1966) Development and evaluation of an impedance cardiac output system. Aerosp. Med., 37: $1208-1212$.

Ledsome, J. R. (1977) The reflex role of pulmonary arterial baroceptors. Am. Rev. Resp. Dis., 115 (Part 2): 245-250.

McCloskey, D. I., Matthews, P. B. C., and Mitchell, J. H. (1972) Absence of appreciable cardiovascular and respiratory response to muscle vibration. J. Appl. Physiol., 33: 623-626. 
McCloskey, D. I. and Mitchell, J. H. (1972) Reflex cardiovascular and respiratory responses originating in exercising muscle. J. Physiol. (Lond.), 224: 173-186.

Miyamoto, Y., Sakakibara, K., Takahashi, M., Tamura, T., TaKahashi, T., Hiura, T., and MIKAMI, T. (1981a) Online computer for assessing respiratory and metabolic function during exercise. Med. Biol. Eng. Comput., 19: 340-348.

Miyamoto, Y., Takahashi, M., Tamura, T., Nakamura, T., Hiura, T., and Mikami, T. (1981b) Continuous determination of cardiac output during exercise by the use of impedance plethysmography. Med. Biol. Eng. Comput., 19: 638-644.

Miyamoto, Y., Hiura, T., Tamura, T., Nakamura, T., Higuchi, J., and Mikami, T. (1982) Dynamics of cardiac, respiratory, and metabolic function in men in response to step work load. J. Appl. Physiol.: Relpir. Environ. Exercise Physiol., 52: 1198-1208.

OTIS, A. B. (1949) Application of Gray's theory of respiratory control to the hyperpnea produced by passive movements of the limbs. J. Appl. Physiol., 1: 743-751.

Paulev, P. (1971) Respiratory and cardiac responses to exercise in man. J. Appl. Physiol., 30: $165-172$.

TIBEs, U. (1977) Reflex inputs to the cardiovascular and respiratory centers from dynamically working canine muscles. Circ. Res., 41 : 332-341.

UCHidA, Y. (1976) Tachypnea after stimulation of afferent cardiac sympathetic nerve fibers. Am. J. Physio!., 230: 1003-1007.

WASSERMAN, K. (1983) Ventilatory control during exercise in man: New concepts. In: Modelling and Control of Breathing, ed. by WhipP, B. J. and WiberG, D. M., Elsevier Publ. Co., New York, pp. 221-228.

Wasserman, K., Whipp, B. J., and Castagna, J. (1974) Cardiodynamic hyperpnea: Hyperpnea secondary to cardiac output increase. J. Appl. Physiol., 36: 457-464.

Wasserman, K., Whipp, B. J., Koyal, S. N., and Cleary, M. G. (1975) Effect of carotid body resection on ventilatory and acid-base control during exercise. J. Appl. Physiol., 39: 354 358.

Wasserman, K., Whipp, B. J., Casaburi, R., Beaver, W. L., and Brown, H. V. (1976) $\mathrm{CO}_{2}$ flow to the lungs and ventilatory control. In: Muscular Exercise and the Lung, ed. by Dempsey, J. A. and ReED, C. E., University of Wisconsin Press, London, pp. 103-135. 